\title{
Evidence that absence of endometrial gland secretions in uterine gland knockout ewes compromises conceptus survival and elongation
}

\author{
C. A. Gray ${ }^{1}$, R. C. Burghardt ${ }^{2}$, G. A. Johnson ${ }^{1 *}$, F. W. Bazer ${ }^{1}$ and \\ T. E. Spencer ${ }^{1+}$ \\ ${ }^{1}$ Center for Animal Biotechnology and Genomics and Department of Animal Science, Texas \\ A\&M University, College Station, Texas 77843-2471, USA; and '2Department of Veterinary \\ Anatomy and Public Health, Texas A\&M University, College Station, Texas 77843-4458,
}

Endometrial glands are necessary for conceptus implantation and growth. In the ovine uterine gland knockout (UGKO) model, blastocysts hatch normally but fail to survive or elongate. This peri-implantation defect in UGKO ewes may be due to the absence of endometrial glands or, alternatively, to the lack of certain epithelial adhesion molecules or the inability of the endometrium to respond to signals from the conceptus. Two studies were performed to examine these hypotheses. In study one, normal $(n=8)$ and UGKO $(n=12)$ ewes were mated at oestrus (day 0) with intact rams and their uteri were flushed 14 days after oestrus. Normal ewes $(n=4)$ were also flushed on 14 days after oestrus. Uterine flushes from bred normal ewes contained filamentous conceptuses ( $n=7$ of 8 ), whereas those from UGKO ewes contained no conceptus ( $n=5$ of 12$)$, a growth-retarded, tubular conceptus ( $n=6$ of 12), or a fragmented, filamentous conceptus ( $n=1$ of 12). In all groups, expression of mucin 1 and integrin $\alpha_{v}, \alpha_{5}, \beta_{3}$ and $\beta_{5}$ was localized at the apical surface of the endometrial luminal epithelium with no detectable differences between normal and UGKO ewes. Uterine flushes from pregnant ewes, but not cyclic or UGKO ewes, contained abundant immunoreactive interferon $\tau$ and the cell adhesion proteins, osteopontin and glycosylation-dependent cell adhesion molecule one. In study two, UGKO ewes were fitted with uterine catheters 5 days after oestrus, infused with recombinant ovine interferon $\tau$ or control proteins from 11 to 15 days after oestrus, and underwent hysterectomy 16 days after oestrus. Expression of several interferon $\tau$-stimulated genes (ISG17, STAT1, STAT2 and IRF-1) was increased in the endometrium from interferon $\tau$-infused UGKO ewes. These results support the hypothesis that the defects in conceptus elongation and survival in UGKO ewes are due to the absence of endometrial glands and their secretions rather than to alterations in expression of anti-adhesive or adhesive molecules on the endometrial luminal epithelium or to the responsiveness of the endometrium to the conceptus pregnancy recognition signal.

\section{Introduction}

Uterine glands are present in the endometrium of all mammalian uteri and develop after birth in many species (for reviews, see Bartol et al., 1999; Gray et al., 2001a). Endometrial glands synthesize, secrete or transport substances that are necessary for conceptus (that is, the embryo-fetus and placental membranes) survival and growth (for reviews, see Bazer, 1975; Roberts and Bazer 1988; Simmen and Simmen, 1990; Fazleabas et al.,

*Present address: Department of Animal and Veterinary Science, Agricultural Biotechnology Building, University of Idaho, Moscow, Idaho 83844-2330, USA

${ }^{+}$Correspondence

Email: tspencer@tamu.edu
1994; Kane et al., 1997; Carson et al., 2000). A role for the endometrial glandular epithelium (GE) has been demonstrated in rodents, in which the absence of glandular secretions, such as leukaemia inhibitory factor and calcitonin, compromised embryo survival by disrupting establishment of uterine receptivity and embryo development (Stewart et al., 1992; Zhu et al., 1998). Similarly, peri-implantation pregnancy loss was observed in the uterine gland knockout (UGKO) ewe model (Gray et al., 2000a, 2001b,c).

The UGKO ewe is a novel model in which endometrial gland morphogenesis has been epigenetically ablated by inappropriate exposure of neonatal ewes to a 19norprogestin from birth to 8 weeks of age (Spencer et al., 1999a; Gray et al., 2000a). The progestin specifically ablates development of the glands within the endometrium without altering development of the uterine myometrium or 
other Müllerian duct-derived female reproductive tract structures (Gray et al., 2000b, 2001b). Despite repeated matings with fertile rams, adult UGKO ewes do not establish pregnancy (Gray et al., 2000a, 2001b,c). Transfer of hatched blastocysts recovered from superovulated normal donor ewes into the uteri of UGKO ewes failed to ameliorate the pregnancy defect (Gray et al., 2001c). Normal hatched blastocysts were found in the uterine flushings of mated UGKO ewes 6 and 9 days, but not 14 days, after mating (Gray et al., 2001b,c). Uterine flushings taken 14 days after mating from mated UGKO ewes contained either no conceptus or a severely growthretarded conceptus that had failed to elongate from a tubular to filamentous form (Gray et al., 2001c). Therefore, UGKO ewes exhibit a peri-implantation pregnancy defect, the timing of which correlates with most of the embryo loss that occurs during pregnancy in livestock and humans (Bazer, 1975; Kane et al., 1997).

Implantation in ruminants is a highly co-ordinated process that involves apposition, attachment, and adhesion of the conceptus trophectoderm to the endometrial luminal epithelium (LE) (Guillomot et al., 1981; Guillomot, 1995). In sheep, the peri-implantation period is marked by rapid elongation of the conceptus from a tubular to filamentous form on days 12-13 of gestation and the production of large amounts of interferon $\tau$ (IFN- $\tau$ ), a type I interferon that is the signal for maternal recognition of pregnancy (Bazer et al., 1997). Elongation of the conceptus is critical for developmentally regulated production of IFN- $\tau$ (Farin et al., 1989) and requires the uterus, as hatched blastocyts fail to elongate in vitro unless transferred to the uterus (Heyman et al., 1984). Apposition of conceptus trophectoderm and endometrial LE is initiated on day 14, adhesion occurs on day 15 , and firm attachment on days 16-18 of gestation (Guillomot et al., 1981). Adhesion of conceptus trophectoderm to the LE is temporally regulated by nonadhesive and adhesive factors on the apical surface of the endometrial LE (Burghardt et al., 1997, in press; Johnson et al., 2001a). It is hypothesized that, initially, nonadhesive factors, such as mucin 1 (Muc-1), sterically impair interactions between adhesive glycoproteins expressed on the apical surfaces of conceptus trophectoderm and LE by means of their extensive glycosylation and extended extracellular structure (Carson et al., 2000; Johnson et al., 2001a). In sheep, immunoreactive Muc-1 expression on the LE decreases progressively between day 9 and day 17 of early pregnancy, presumably to unmask adhesive glycoproteins on the LE for interaction with the trophectoderm (Johnson et al., 2001a). Integrins are thought to be the dominant glycoproteins that regulate trophectoderm adhesion. During the peri-implantation period in ewes, integrin subunits $\alpha_{v}, \alpha_{4}, \alpha_{5}, \beta_{1}, \beta_{3}$ and $\beta_{5}$ were constitutively expressed on the conceptus trophectoderm as well as the apical surface of the endometrial LE Johnson et al., 2001a). During the peri-implantation period, in addition to constitutive expression of integrins, two molecules involved in cell adhesion, osteopontin (Johnson et al., 1999a,b, 2001a) and glycosylation-dependent cell adhesion molecule 1 (GlyCAM-1) (Spencer et al., 1999b), are secreted by the endometrial GE and are thought to bind to trophectoderm and LE to stimulate elongation, adhesion and attachment of the ovine conceptus (Johnson et al., 2001a).

The available evidence supports the hypothesis that the failure of peri-implantation conceptus survival and elongation in UGKO ewes is due to an absence of endometrial glands and, by default, their secretory products. Alternatively, the pregnancy defect in UGKO ewes could be attributed to deficient expression of adhesion molecules on the LE or inability of the endometrium to respond to conceptus signals such as IFN- $\tau$. Two studies were conducted to test these hypotheses by determining differences in normal and UGKO ewes on: (1) distribution of Muc- 1 and integrin subunit expression in the uterine LE 14 days after mating; (2) abundance of osteopontin and GlyCAM- 1 in the uterine lumen 14 days after mating; and (3) endometrial expression of IFN- $\tau$-stimulated genes in response to intrauterine administration of recombinant ovine IFN- $\tau$.

\section{Materials and Methods}

\section{Animals}

Experimental and surgical procedures complied with the Guide for Care and Use of Agriculture Animals and were approved by the Institutional Agricultural Animal Care and Use Committee of the Texas A\&M University System Agricultural Experiment Station (Animal Use Protocol 7286).

UGKO ewes were produced as described by Spencer et al. (1999a) and Gray et al. (2000a) by implanting crossbred Rambouillet ewe lambs with a single Synchromate $B \mathbb{R}$ (Sanofi, Overland Park, KS) implant within $12 \mathrm{~h}$ of birth and every 2 weeks thereafter for a total of 8 weeks. Implants were inserted s.c. into the periscapular area and released approximately $6 \mathrm{mg}$ norgestomet $(17 \alpha$-acetoxy- $11 \beta$ methyl-19-norpreg-4-ene-3,20-dione), a potent synthetic 19-norprogestin, over 14 days (Bartol et al., 1988). Normal control ewes did not receive implants.

\section{Study one}

Adult UGKO $(n=18)$ and normal ewes $(n=12)$ were given two i.m. injections (at 07:00 and 17:00 h) of $10 \mathrm{mg}$ prostaglandin $\mathrm{F}_{2 \alpha}$ (Lutalyse, Upjohn, Kalamazoo, MI) 9 days apart to synchronize oestrus. Ewes were monitored each day for oestrous behaviour using vasectomized rams. All UGKO and some normal control ewes $(n=8)$ were mated at oestrus (day 0 ) and at 12 and $24 \mathrm{~h}$ after oestrus with intact rams of proven fertility. The remaining normal control ewes $(n=4)$ were assigned to cyclic status, and oestrus was determined using vasectomized rams.

Fourteen days after oestrus or mating, all ewes were subjected to mid-ventral laparotomy, and their uterine 
lumina were flushed with $20 \mathrm{ml}$ sterile saline. Uterine flushes were analysed under a dissecting microscope to recover conceptuses, if any, and determine their morphology. Conceptuses were fixed in $4 \%$ paraformaldehyde in PBS $(\mathrm{pH}$ 7.2). Uterine flushes were clarified by centrifugation (2000 $\mathrm{g}$ for $30 \mathrm{~min}$ at $4^{\circ} \mathrm{C}$ ), and aliquots were snap-frozen in liquid nitrogen and stored at $-80^{\circ} \mathrm{C}$. Several sections $(1-1.5 \mathrm{~cm})$ from the middle of each uterine horn were snap-frozen in Tissue-Tek OCT compound (Miles, Oneonta, NY). Several sections from the middle region of each uterine horn were also fixed in $4 \%$ paraformaldehyde in PBS ( $\mathrm{pH} \mathrm{7.2).} \mathrm{After} 24 \mathrm{~h}$, fixed tissues were changed to $70 \%$ ethanol for $24 \mathrm{~h}$ and then dehydrated and embedded in Paraplast-Plus (Oxford Labware, St Louis, $\mathrm{MO})$. The endometrium was physically dissected from myometrium from the remainder of each uterine horn ipsilateral to the ovary bearing the corpus luteum and then snap-frozen in liquid nitrogen and stored at $-80^{\circ} \mathrm{C}$ for RNA extraction.

\section{Study two}

Fourteen days after mating, another group of UGKO ewes ( $n=8)$ was subjected to mid-ventral laparotomy, their uterine lumina flushed with $20 \mathrm{ml}$ sterile saline, and their uterine horns fitted with catheters as described by Spencer et al. (1995). Ewes were given two i.m. injections (07:00 and 17:00 h) of $10 \mathrm{mg}$ prostaglandin $\mathrm{F}_{2 \alpha}$ (Lutalyse, Upjohn, Kalamazoo, MI) to synchronize oestrus, and were monitored twice a day for oestrous behaviour using a vasectomized ram, and then assigned randomly to receive daily intra-uterine injections (at 07:00 and 19:00 h each day) of control proteins ( $6 \mathrm{mg}$ serum proteins per day) or recombinant ovine IFN- $\tau$ (rolFN- $\tau$; $2 \times 10^{7}$ antiviral units per day) from day 11 to day 15 after mating. Recombinant olFN- $\tau$ was produced from a synthetic gene construct in Pichia pastoris and purified as described by Van Heeke et al. (1996). Preparation of control proteins and rolFN- $\tau$ was performed as described by Spencer et al. (1995). Blood samples were collected on days 11-15 after mating, via jugular venepuncture into Vacutainer evacuated blood collection tubes with sodium heparin (Becton-Dickinson, Franklin Lakes, NJ), and plasma was stored at $-20^{\circ} \mathrm{C}$. All ewes were hysterectomized 16 days after mating. At hysterectomy, portions (approximately $1.0 \mathrm{~cm}$ ) from the middle region of each uterine horn were fixed in fresh $4 \%$ paraformaldehyde in PBS for $24 \mathrm{~h}$ and embedded in Paraplast-Plus (Oxford Labware). From the remainder of each uterine horn, endometrium was dissected from myometrium, frozen separately in liquid nitrogen, and stored at $-80^{\circ} \mathrm{C}$.

\section{Histological analyses}

Conceptus tissues were sectioned $(5 \mu \mathrm{m})$ and stained with haematoxylin and eosin as described by Gray et al. (2000a). Uteri were sectioned $(5 \mu \mathrm{m})$ and stained with Masson's trichrome stain. This procedure stains nuclei black, cytoplasm and muscle fibres red, and extracellular matrix (ECM) components blue. For this stain, uterine sections were deparaffinized in CitraSolv (Fisher Scientific; Fairlawn, NJ) and rehydrated through a graded alcohol series to distilled water. Tissues were then incubated for $1 \mathrm{~h}$ at $55^{\circ} \mathrm{C}$ in Bouin's solution $(71 \%$ (v/v) picric acid, $24 \%$ formaldehyde (40\%), and 5\% (v/v) glacial acetic acid) and rinsed in water. Slides were incubated sequentially at room temperature for 5 min each in Weigert's iron haematoxylin (50\% (v/v) ethanol (95\%), 4\% (v/v) ferric chloride $(29 \%$ aqueous), $1 \%$ (v/v) hydrochloric acid, and 1\% (w/v) haematoxylin), biebrich scarlet-acid fuchsin solution $(90 \%$ $(\mathrm{v} / \mathrm{v})$ biebrich scarlet (1\% aqueous), 9\% (v/v) acid fuchsin ( $1 \%$ aqueous), and $1 \%(\mathrm{v} / \mathrm{v})$ glacial acetic acid), phosphomolybdic-phosphotungstic acid solution $(2.5 \%$ ( $/ \mathrm{v})$ phosphomolybdic acid, 2.5\% (w/v) phosphotungstic acid), aniline blue solution (2.5\% (w/v) aniline blue, 2\% ( $\mathrm{v} / \mathrm{v})$ glacial acetic acid), and then in $1 \%$ glacial acetic acid $(\mathrm{v} / \mathrm{v})$ for $5 \mathrm{~min}$. Slides were then dehydrated through alcohol to xylene, and coverslips fixed with Permount (Fisher Scientific, Fair Lawn, NJ). Photomicrographs of stained tissues were captured using a Zeiss Axioplan2 photomicroscope (New York, NY) fitted with a Hamamatsu chilled 3CCD colour camera (Hamamatsu, Hamamatsu City).

\section{Western blot analyses}

Uterine flushes $(2 \mathrm{ml})$ from day 14 cyclic, pregnant and UGKO ewes were concentrated using Centricon-3 columns (Amicon, Beverly, MA). Protein content was determined using a Bradford protein assay (Bio-Rad, Hercules, CA) with bovine serum albumin (BSA) as the standard. Uterine flush proteins $(30 \mu \mathrm{g})$ were denatured, separated by SDS-PAGE using $12 \%$ acrylamide gels, and transferred to nitrocellulose membranes as described by Spencer et al. (1999b). Membranes were blocked for $1 \mathrm{~h}$ at room temperature with $5 \%(\mathrm{w} / \mathrm{v})$ milk-TBST (20 mmol Tris $\mathrm{I}^{-1}$ ( $\left.\mathrm{pH} 7.5\right), 137 \mathrm{mmol}$ $\mathrm{NaCl} \mathrm{I}^{-1}, 0.05 \%(\mathrm{v} / \mathrm{v})$ Tween 20) and then incubated with mouse anti-ovine IFN- $\tau$ (HL129; $4 \mu \mathrm{g} \mathrm{ml}^{-1}$ ) (Swann et al., 1999), rabbit anti-human osteopontin (LF-123 and LF-124; 1 : 2500 each) (Johnson et al., 1999a), or rabbit anti-rat GlyCAM-1 (CAM02; $1 \mu \mathrm{g} \mathrm{ml}^{-1}$; kindly provided by S. D. Rosen (University of California) (Singer and Rosen, 1996) in 5\% milk-TBST as described by Spencer et al. (1999b). Negative control blots were performed in which primary antibody was replaced by mouse IgG (IFN- $\tau$ ), rabbit IgG (GlyCAM-1) or normal rabbit serum (osteopontin) at the same concentration used for the respective primary antibodies. After an overnight incubation at $4^{\circ} \mathrm{C}$, membranes were washed for 30 min with TBST and then incubated with either goat anti-mouse or goat anti-rabbit IgG-horseradish peroxidase-conjugated secondary antibody (KPL, Bethesda, $\mathrm{MD})$ for $1 \mathrm{~h}$ at room temperature. Membranes were again washed with TBST for 30 min before detection by chemiluminescence using a Super Signal West Pico kit (Pierce; Rockford, IL) and Kodak X-OMAT AR film. 


\section{Immunocytochemical analyses}

Antibodies used for immunocytochemistry included rabbit anti-Muc-1 (generously provided by D. Carson, University of Delaware); rabbit anti- $\alpha_{v}$ (AB1930), $\alpha_{5}$ (AB1928), $\beta_{3}$ (AB1932), and $\beta_{5}$ (AB1926) from Chemicon (Temecula, CA); normal rabbit IgG (15006) from Sigma (St Louis, MO); and fluorescein-conjugated goat anti-rabbit IgG (65-611) from Zymed (San Francisco, CA).

Proteins were localized in frozen uterine tissue sections (8-10 $\mu \mathrm{m})$ by immunofluorescence staining as described by Johnson et al. (2001a). Briefly, frozen uterine tissues were sectioned $(8 \mu \mathrm{m})$ with a Hacker-Bright OTF cryostat (Hacker Instruments, Fairfield, NJ) and mounted on Superfrost/Plus microscope slides (Fisher Scientific, Pittsburgh, PA). Frozen sections were fixed in $-20^{\circ} \mathrm{C}$ methanol for $10 \mathrm{~min}$, permeabilized with $0.3 \%(\mathrm{v} / \mathrm{v})$ Tween-20 in 0.02 M PBS, and then blocked in antibody dilution buffer (two parts 0.02 mol PBS ${ }^{-1}, 1.0 \%$ BSA, $0.3 \%$ Tween-20 ( $\mathrm{pH} 8.0)$ and one part glycerol) containing $5 \%$ normal goat serum for $1 \mathrm{~h}$ at room temperature. Immunoreactive protein was then detected using a fluorescein-conjugated secondary antibody for $1 \mathrm{~h}$ at room temperature. Slides were overlaid with Prolong antifade mounting reagent and then coverslips were added (Molecular Probes, Eugene, OR). Representative fluorescence images of cross-sections for each antibody and for each ewe were recorded digitally.

\section{Progesterone radioimmunoassay}

Concentrations of progesterone in plasma samples were determined using an Active Progesterone Radioimmunoassay kit (Diagnostic Systems Laboratories, Webster, TX) as described by Gray et al. (2000a). Assay sensitivity was $0.1 \mathrm{ng} \mathrm{ml}^{-1}$, and the intra-assay coefficient of variation was $5 \%$.

\section{RNA isolation and analyses}

Total cellular RNA was isolated from frozen endometrium using the Trizol reagent (Gibco-BRL, Grand Island, NY) and analysed for concentration and quality. Denatured total cellular RNA ( $20 \mu \mathrm{g}$ ) for each ewe was analysed by slot blot hybridization using radiolabelled antisense cRNA probes generated by transcription in vitro with $\left[\alpha_{-}^{32} \mathrm{P}\right]$ UTP (Amersham Pharmacia Biotech, Piscataway, NJ) as described by Spencer et al. (1995). Plasmid templates containing cDNAs for ovine IFN-stimulated gene 17 (ISG17; kindly provided by T. Hansen, University of Wyoming), human signal transducer and activator of transcription (STAT) 1, human STAT2, ovine IFN regulatory factor one (IRF-1), and 18S rRNA (pT718S; Ambion, Austin, TX) were used to produce radiolabelled cRNA probes as described by Choi et al. (2001). Hybridization signals were detected by exposing washed slot blots to a phosphoimager screen and visualized using a Typhoon 8600 Variable Mode Imager (Molecular Dynamics, Sunnyvale, CA).

\section{Statistical analyses}

All quantitative data were subjected to least-squares analysis of variance (LS-ANOVA) using General Linear Models procedures of the Statistical Analysis System (SAS, 1990). Analyses of steady-state amounts of endometrial mRNA determined by slot blot hybridization included the $18 \mathrm{~S}$ rRNA as a covariate in LS-ANOVA to correct for differences in sample loading. In all analyses, error terms used in tests of significance were identified according to the expectation of the mean squares for error (Steele and Torrie, 1980). Data are presented as least-squares means with overall SE.

\section{Results}

\section{Study one: conceptus morphology in uterine flushes}

One to three filamentous conceptuses were present in the uterine flushes of most normal mated control ewes ( $n=7$ of 8 ) mated with an intact fertile ram. The uterine flushes of UGKO ewes contained either no conceptus ( $n=5$ of 12) or degenerating conceptuses ( $n=7$ of 12 ). The conceptus morphology in UGKO uterine flushes was classified as fragmented filamentous $(n=1)$ or degenerating tubular $(n=6)$.

\section{Study one: histoarchitecture of the uterus}

Uteri of all control ewes exhibited extensive, normal gland development in the intercaruncular endometrium (Fig. 1a-d). As expected, none of the UGKO ewes displayed uterine gland development characteristic of controls (Fig. 1e,f). In UGKO ewes, uterine glands were most often either absent or sporadically distributed at very low density. In uteri from normal day 14 cyclic and pregnant ewes, caruncular areas of the endometria consisted of densely packed stromal cells and showed decreased staining for ECM components as compared with the intercaruncular areas of the endometrium. The stroma of the intercaruncular endometrium in ruminants can be divided into the stratum compactum beneath the LE, consisting of densely packed stroma, and the stratum spongiosum nearer the myometrium, consisting of less dense stroma. The stratum spongiosum of the intercaruncular endometrium of normal ewes contained many endometrial glands and showed pronounced ECM compared with the stroma in the stratum compactum zone and caruncular area. In comparison, endometrium of uteri from UGKO ewes was most similar to that of the caruncular area of the uteri of control ewes, because it lacked characteristic intercaruncular endometrium. Furthermore, the lumen of the uterus was greater in width with the caruncular areas not protruding as far into the uterine lumen, as observed in the uteri of normal ewes. The UGKO endometrium consisted primarily of dense stromal cells with very little detectable ECM except in the deep stroma on the border of the myometrium. This area in which ECM staining was detected corresponds to the area in which large numbers of blood vessels are present. 

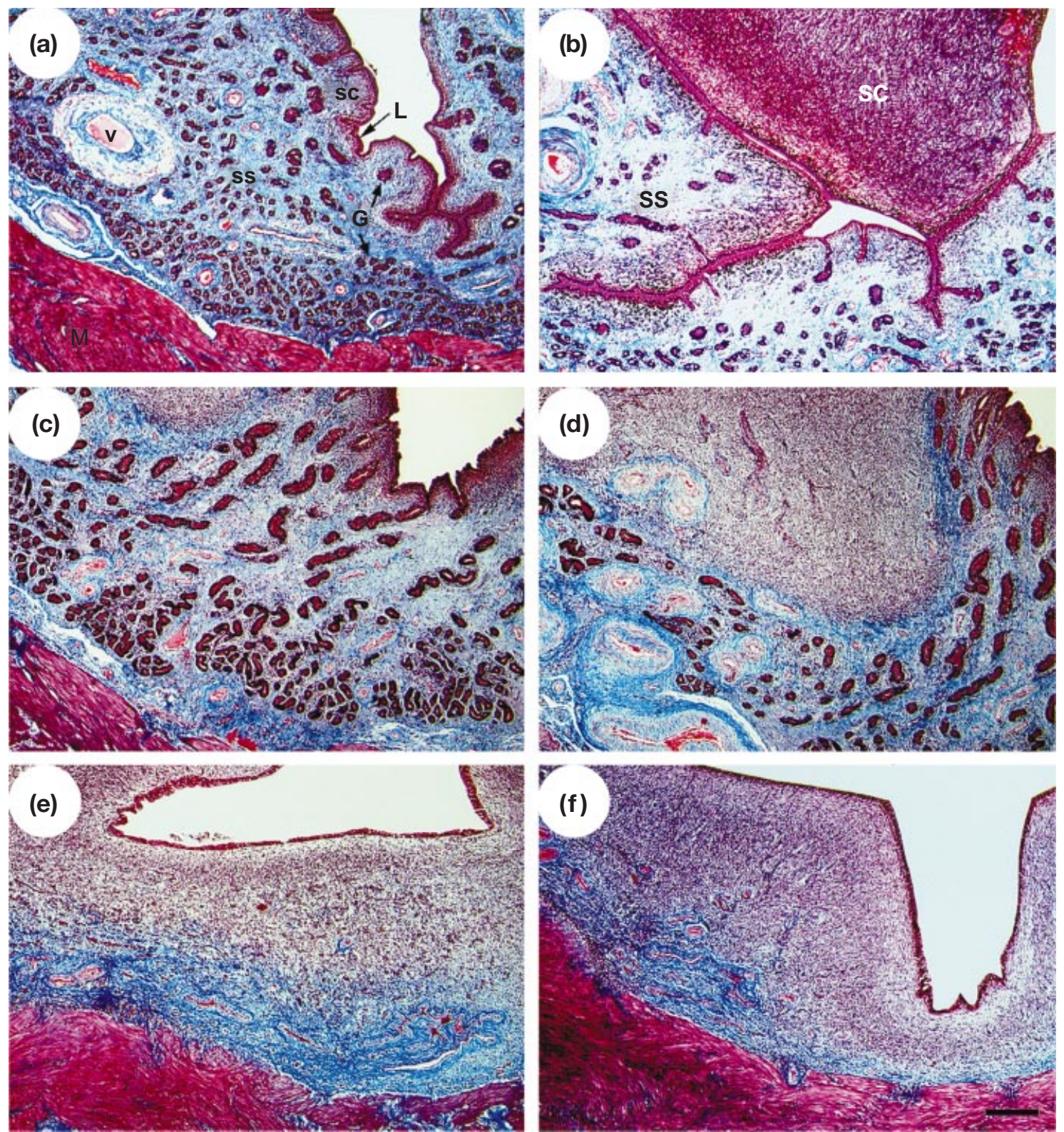

Fig. 1. Representative photomicrographs of the uterus from cyclic $(a, b)$, pregnant $(c, d)$ and uterine gland knockout (UGKO) ewes (e,f) 14 days after mating, using a Masson's trichrome stain. This procedure stains nuclei black, cytoplasm and muscle fibres red, and extracellular matrix (ECM) components blue. The left column $(\mathrm{a}, \mathrm{c})$ from normal ewes depicts intercaruncular endometrial regions and the right column $(b, d)$ depicts caruncular endometrial areas. No distinct caruncular or intercaruncular regions are distinguishable in uteri from UGKO ewes (e,f). L: luminal epithelium; G: glandular epithelium; SC: stratum compactum; SS: stratum spongiosum; M: myometrium; V: blood vessel. Scale bar represents $200 \mu \mathrm{m}$.

Myometrial histoarchitecture did not appear different between uteri from UGKO and control ewes.

\section{Study one: IFN- $\tau$, osteopontin and GlyCAM-1 in uterine flushes}

Filamentous conceptuses were present in most uterine flushes from normal ewes 14 days after mating (Fig. 2a). In contrast, growth-retarded conceptuses were observed in the uterine flush of some UGKO ewes. A representative degenerating tubular conceptus found in the uterine flush of an UGKO ewe is shown (Fig. 2C).

Immunoreactive IFN- $\tau$ was absent in uterine flushes obtained from cyclic ewes (Fig. 2b, lanes 1-4), but detected in uterine flushes obtained from pregnant ewes (Fig. 2b, lanes 5-8). The amount of IFN- $\tau$ present in the uterine 
(a)

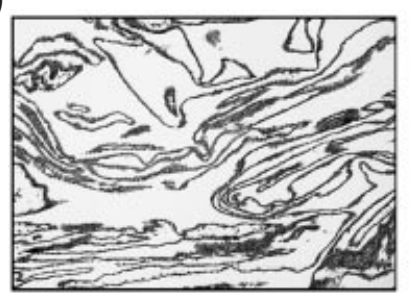

(c)

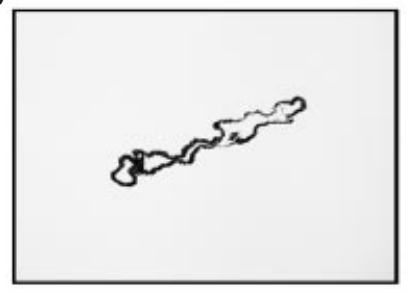

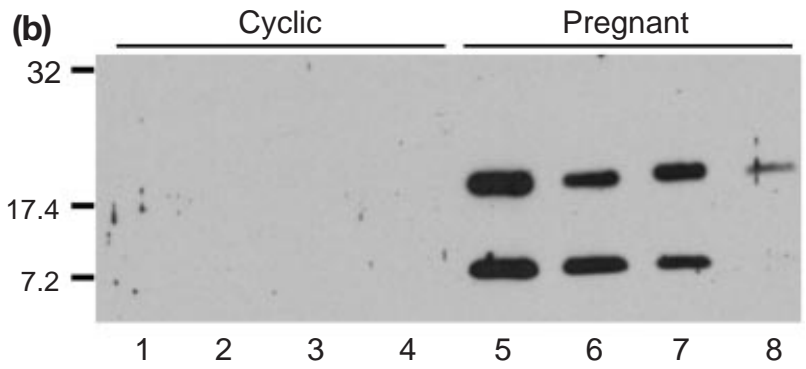

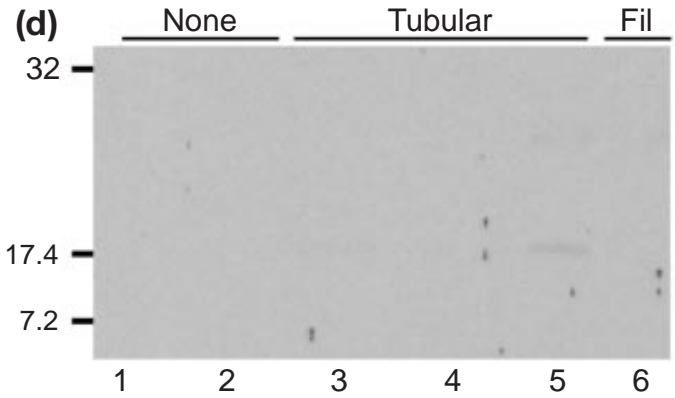

Fig. 2. Conceptus morphology and uterine flush content of interferon $\tau$ (IFN- $\tau$ ) from cyclic, pregnant and uterine gland knockout (UGKO) ewes. Photomicrographs $(\mathrm{a}, \mathrm{c})$ are haematoxylin and eosin-stained conceptuses that were present in the uterine flushes. (a) Elongating filamentous conceptus representative of conceptuses found in the uterine flushes from normal bred ewes 14 days after mating. (c) Growth-retarded, or tubular, conceptus detected in the uterine flush of an UGKO ewe 14 days after mating. Photomicrographs are shown at the same magnification $(\times 164)$. (b,d) Western blot analyses of IFN- $\tau$ in concentrated uterine flushes obtained from (b) normal ewes on day 14 of oestrus (Cyclic, lanes 1-4) or 14 days after mating (Pregnant, lanes 5-8) and (d) UGKO ewes 14 days after mating. (d) Uterine flushings from UGKO ewes were loaded depending upon the morphology of the conceptus present in the uterine flush. No conceptus (lanes 1-2), a growth-retarded or degenerating tubular conceptus (lanes 3-5), or a fragmented filamentous conceptus (Fil; lane 6) was detected in the uterine flushes from UGKO ewes. Each lane in the blots represents proteins from a single flush from an individual ewe (30 $\mu$ g per lane). Immunoreactive protein was detected using mouse monoclonal antibody directed against ovine IFN- $\tau$. Positions of pre-stained molecular weight standards $\left(\times 10^{-3}\right)$ are indicated.

flushes corresponded to the number of conceptuses present in the uterine flush. The uterine flush from the ewe represented in lane 5 contained three filamentous conceptuses, whereas those in lanes 6 and 7 were from ewes with two conceptuses, and lane 8 represents a flush that contained a single conceptus. Western blot analyses of uterine flushes that contained a conceptus from UGKO ewes is presented (Fig. 2d). Immunoreactive IFN- $\tau$ was not detected in uterine flushes from UGKO ewes containing no conceptus (lanes 1 and 2), degenerating tubular conceptuses (lanes 3 and 4), or a fragmenting filamentous conceptus (lane 6). Immunoreactive IFN- $\tau$ was within detection limits in the uterine flush of one UGKO ewe that contained a degenerating, tubular conceptus (lane 5).

Immunoreactive osteopontin was absent in uterine flushings from cyclic ewes (Fig. 3a, lanes 1-4), but present in uterine flushings from pregnant ewes (Fig. 3a, lanes 5-8). Several molecular mass forms $(70,45$, and $25 \mathrm{kDa})$ of immunoreactive osteopontin were detected in the uterine flushings from pregnant ewes. The 45 and $25 \mathrm{kDa}$ forms of osteopontin are cleavage products of the $70 \mathrm{kDa}$ form
(Johnson et al., 1999a). The $70 \mathrm{kDa}$ form of osteopontin was present in only one uterine flush (Fig. 3a, lane 5), which contained three filamentous conceptuses. Immunoreactive osteopontin was not detectable in any uterine flush obtained from UGKO ewes, regardless of the presence of a degenerating conceptus (Fig. 3b, lanes 1-6).

Immunoreactive GlyCAM-1 was detectable in two of the uterine flushes obtained from cyclic ewes (Fig. 4a, lanes 2 and 4), but abundant in all uterine flushes obtained from pregnant ewes (Fig. 4a, lanes 5-8). Small amounts of GlyCAM-1 were detected in uterine flushings from three UGKO ewes (Fig. 4b, lanes 1, 3 and 5). However, the amount of GlyCAM- 1 in uterine flushings from UGKO ewes was not abundant and appeared similar to that in normal cyclic ewes.

\section{Study one: expression of Muc-1 and integrin subunits in the endometrium}

Immunoreactive Muc-1 was restricted to the apical surface of uterine LE and GE (Fig. 5). Apical staining of 

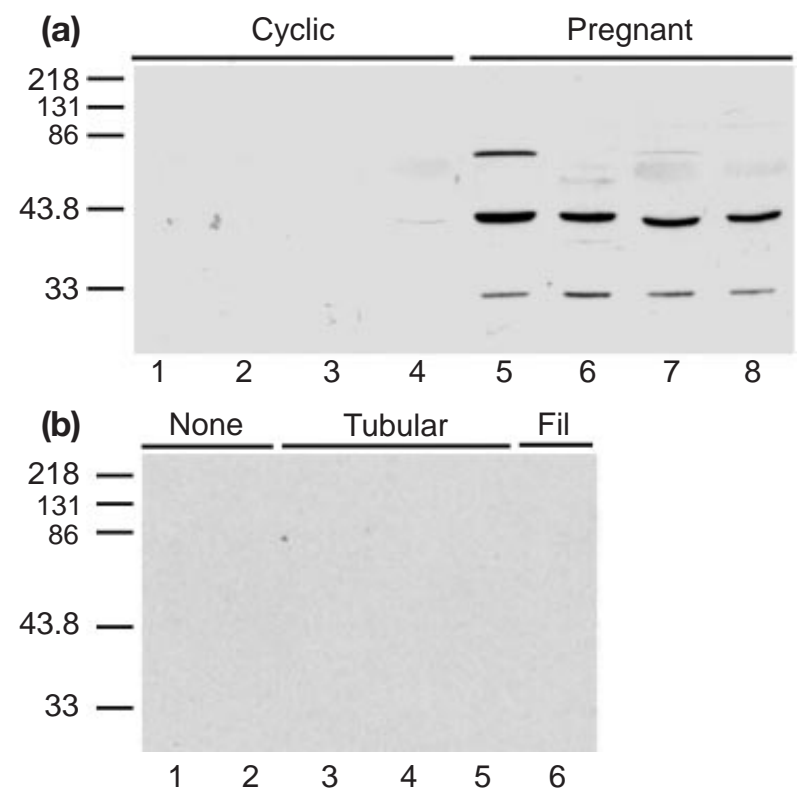

Fig. 3. Western blot analyses of osteopontin in concentrated uterine flushes obtained from (a) normal ewes on day 14 of oestrus (Cyclic, lanes 1-4) or 14 days after mating (Pregnant, lanes 5-8) and (b) uterine gland knockout (UGKO) ewes 14 days after mating. Flushes from UGKO ewes were loaded depending upon the morphology of the conceptus present in the uterine flush. No conceptus (lanes 1-2), a growth-retarded or degenerating tubular conceptus (lanes 3-5), or a fragile filamentous conceptus (Fil; lane 6) was detected in the uterine flushes from UGKO ewes. Each lane in the blots represents a single flush from an individual ewe $(30 \mu \mathrm{g}$ per lane). Immunoreactive protein was detected using a cocktail of polyclonal rabbit anti-human osteopontin IgG (LF-123 and LF124). Positions of pre-stained molecular weight standards $\left(\times 10^{-3}\right)$ are indicated.

Muc-1 was detected on the LE of all uteri and was not appreciably different in comparisons among uteri from cyclic, pregnant and UGKO ewes. Immunoreactive $\alpha_{v}$, $\alpha_{4}, \alpha_{5}, \beta_{3}$ and $\beta_{5}$ integrin subunits were detected at the apical surface of uterine LE and GE of normal cyclic and pregnant ewes (Fig. 5) and were not affected by pregnancy status in normal ewes. Overall, the relative intensity of immunoreactive integrin subunit expression was not different in the LE of the endometrium of UGKO ewes compared with that for normal cyclic and pregnant ewes.

\section{Study two: peripheral plasma concentrations of progesterone}

Concentrations of progesterone in plasma obtained each day during the intra-uterine infusion period were not affected by treatment (day $\times$ treatment, $P=0.628$ ). Plasma progesterone concentrations remained constant throughout the uterine infusion of either control proteins or rolFN- $\tau$.
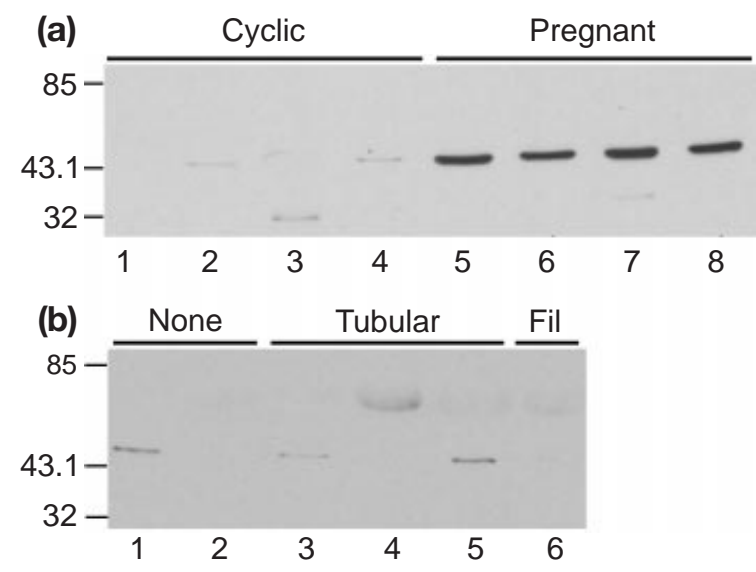

Fig. 4. Western blot analyses of glycosylation-dependent cell adhesion molecule 1 (GlyCAM-1) in concentrated uterine flushes obtained on from (a) normal ewes on day 14 of oestrus (Cyclic, lanes 1-4) or 14 days after mating (Pregnant, lanes 5-8) and (b) uterine gland knockout (UGKO) ewes. Flushes from UGKO ewes were loaded depending upon the morphology of the conceptus present in the uterine flush. No conceptus (lanes 1-2), a growthretarded or degenerating tubular conceptus (lanes 3-5), or a fragmenting filamentous conceptus (Fil; lane 6) was detected in the uterine flushes from UGKO ewes. Each lane in the blots represents a single flush from an individual ewe (30 $\mu$ g per lane). Immunoreactive protein was detected using rabbit anti-rat GlyCAM-1 (CAM02) IgG. Positions of pre-stained molecular weight standards $\left(\times 10^{-3}\right)$ are indicated.

\section{Study two: steady-state concentrations of mRNAs} encoding interferon-stimulated gene in the endometrium

Results of the slot blot hybridization analyses to determine steady state levels of endometrial mRNAs are summarized (Table 1). Infusion of rolFN- $\tau$ into the uterus of UGKO ewes increased endometrial concentrations of ISG17 $(P<0.001)$, STAT1 $(P<0.001)$, STAT2 $(P<0.001)$ and IRF-1 $(P<0.003)$ as compared with endometrium from ewes infused with control proteins.

\section{Discussion}

The results of the present study extend previous reports describing both gross and histological differences between uteri from normal and UGKO ewes, including differences in the stromal organization of the endometria of UGKO ewes (Gray et al., 2000b, 2001b). The present results are the first to indicate that uteri of adult UGKO ewes, which lack an intercaruncular area consisting entirely of compact stroma, also have major differences in expression of ECM components as assessed by Masson's trichrome staining.

Gray et al. (2001c) found that normal conceptuses were present in the uterine lumen of UGKO ewes on days 6 and 9 , but not on day 14 , after mating. Similarly, in the present study, uterine flushings of UGKO ewes contained either no 


\section{Cyclic}
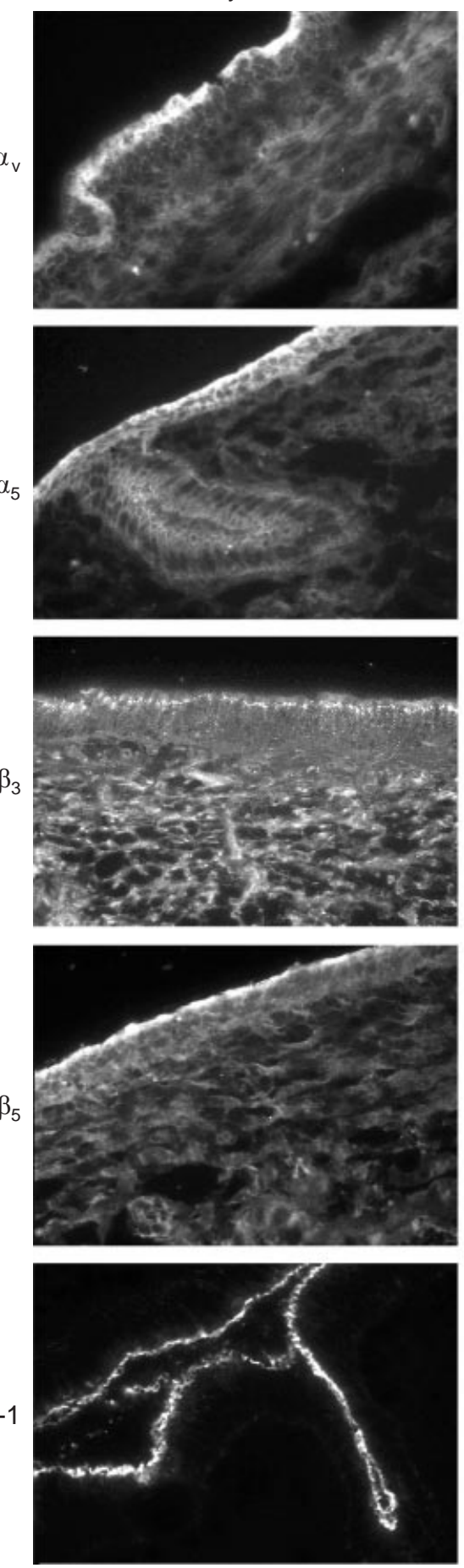

\section{Pregnant}
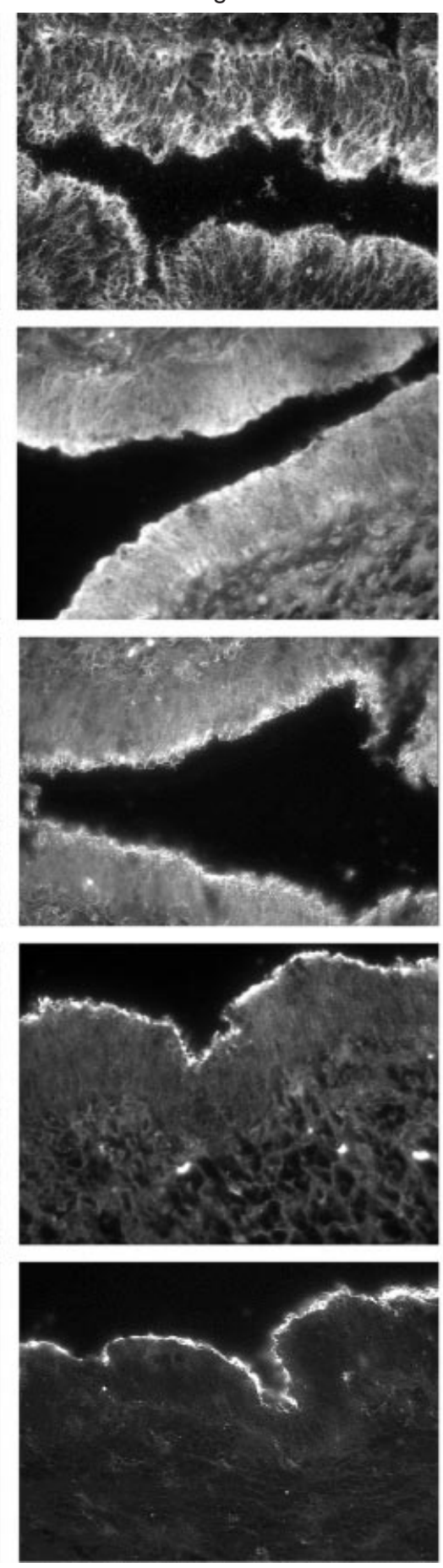

UGKO
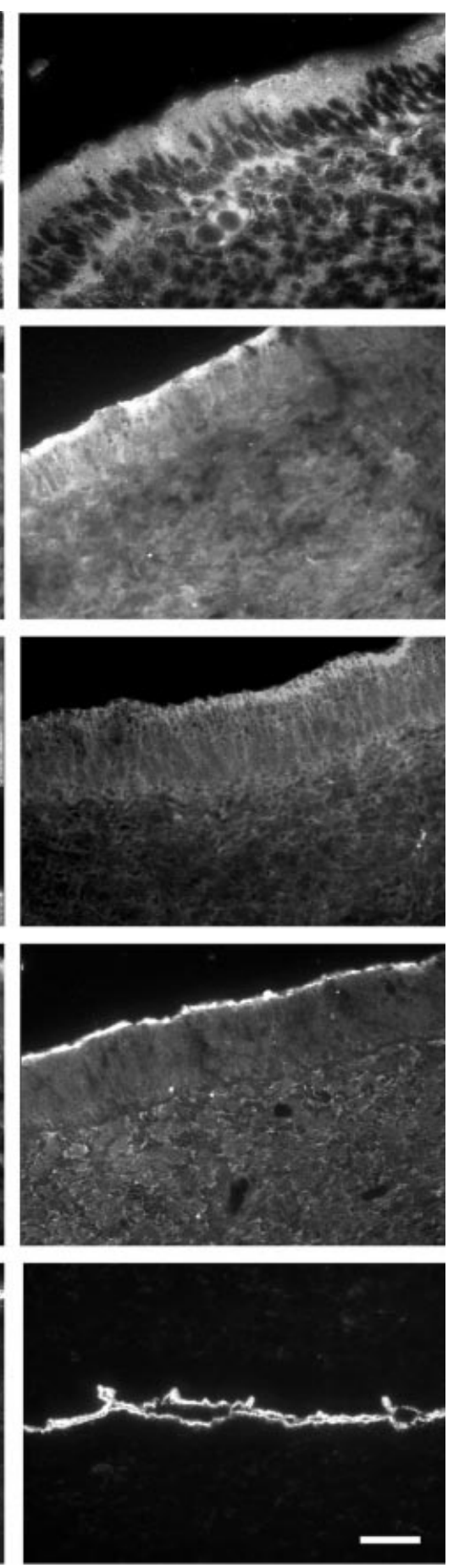

Fig. 5. Immunofluorescent localization of integrins $\alpha_{v}, \alpha_{5}, \beta_{3}, \beta_{5}$ and MUC-1 in the endometrium of normal ewes on day 14 of oestrus (Cyclic; left column) or 14 days after mating (Pregnant; middle column), or uterine gland knockout (UGKO) ewes after mating (UGKO; right column). Frozen cross-sections of the uterine wall from control and UGKO ewes were fixed in methanol and blocked in $5 \%$ normal goat serum. Sections were incubated overnight at $4^{\circ} \mathrm{C}$ with $20 \mu \mathrm{g} \mathrm{ml}^{-1}$ rabbit $\operatorname{lgG}$ against $\alpha_{v}, \alpha_{5}, \beta_{3}, \beta_{5}$ or MUC-1, and then incubated with fluorescein-conjugated goat anti-rabbit lgG. Photomicrographs were taken using a fluorescein filter. Scale bar represents $200 \mu \mathrm{m}$. 
Table 1. Steady state concentrations of endometrial mRNA encoding interferon (IFN)-stimulated gene 17 (ISG17), signal transducer and activator of transcription 1 (STAT1), STAT2, and IFN regulatory factor 1 (IRF-1)

\begin{tabular}{|c|c|c|c|c|}
\hline \multirow{2}{*}{$\begin{array}{l}\text { Intrauterine protein } \\
\text { treatment }\end{array}$} & \multicolumn{4}{|c|}{ Endometrial expression of mRNA ${ }^{a}$} \\
\hline & ISG17 & STAT1 & STAT2 & IRF-1 \\
\hline Control & 218053 & 7728198 & 443682 & 602494 \\
\hline $\operatorname{rolFN}-\tau$ & 3086827 & 31034609 & 2668866 & 1059946 \\
\hline Overall SE & 102246 & 669813 & 31321 & 41152 \\
\hline$P$ value $^{b}$ & 0.001 & 0.001 & 0.001 & 0.003 \\
\hline Fold increase & 14 & 4 & 6 & 2 \\
\hline
\end{tabular}

a Data are presented as relative light units with SE.

bOne-way ANOVA (Control versus IFN- $\tau$ ).

conceptus or a growth-retarded conceptus on day 14 after mating. Taken together, the evidence indicates that endometrial glands and, by default, their secretions are not required for development of the conceptus to the hatched blastocyst state, but are crucial for blastocyst elongation. Normal conceptuses by day 14 after mating have developed from a tubular to an elongated filamentous form, secreted large amounts of IFN- $\tau$, and transiently contacted the maternal epithelium in preparation for implantation (Guillomot, 1995).

In the present study, uterine flushes from UGKO ewes on day 14 after mating had either no detectable or very low amounts of IFN- $\tau$ associated with severely growth retarded conceptuses. Secretion of IFN- $\tau$ by the trophectoderm serves as a marker for conceptus health and state of development. IFN- $\tau$ is secreted by the ovine conceptus between days 8 and 21 after mating, with maximum amounts secreted on days 14-16 as the conceptus develops from a tubular to a filamentous form (Ashworth and Bazer, 1989; Farin et al., 1989). In the present study, the uterine flush of UGKO ewes did not contain the high concentrations of immunoreactive IFN- $\tau$ characteristic of uterine flushings from normal ewes on day 14 after mating. The lack of appreciable IFN- $\tau$ in the uterine flush of UGKO ewes is correlated directly with the lack of a conceptus or the presence of a growth-retarded tubular conceptus in the uteri of $U G K O$ ewes.

In ewes, IFN- $\tau$ acts on the endometrium to induce or increase the expression of several inteferon-stimulated genes. IFN- $\tau$-stimulated genes include ISG17/ubiquitin crossreactive protein (Johnson et al., 1999b, 2000), 2', 5'oligoadenylate synthetase (OAS) (Mirando et al., 1991; Johnson et al., 2001b; Stewart et al., 2001a), STATs 1 and 2 (Choi et al., 2001; Stewart et al., 2001a,b), and IRF-1 and -9 (Choi et al., 2001; Stewart et al., 2002). Despite retarded conceptus development and absence of IFN- $\tau$ production by UGKO conceptuses, findings from the present study indicate that the endometrium of UGKO ewes is responsive to IFN- $\tau$ in terms of induction of or increases in expression of IFN- $\tau$-stimulated genes. The ability of IFN- $\tau$ to stimulate increases in IFN- $\tau$-stimulated genes in the UGKO uterus is in agreement with previous studies in normal cyclic ewes infused with IFN- $\tau$ (Spencer et al., 1999c; Johnson et al., 2000; Choi et al., 2001). Taken together, available results indicate that the endometrium of UGKO ewes can respond properly to the pregnancy recognition signal produced by the ovine conceptus, but is unable to produce the proper secretions to stimulate conceptus development.

The process of superficial implantation in sheep involves a sequence of events, including removal of anti-adhesion molecules on the LE, expression of receptors on the LE and trophectoderm, and secretion of adhesive factors by the endometrial LE and GE (Bowen and Burghardt 2000; Johnson et al., 2001a; Burghardt et al., in press). Muc-1 is a heavily glycosylated mucin thought to project above the apical surface of LE cells to sterically block cell-cell and cell-ECM adhesion (Wesseling et al., 1995) and, thereby, trophectoderm access to the uterine LE. In both humans and rodents, the expression pattern of glycoproteins, such as MUC-1, on the uterine LE may control the accessibility of integrin receptors to their ligands and provide a barrier to invasiveness (Carson et al., 2000). The implantation adhesion cascade in rodents is initiated after downregulation of MUC-1 (Carson et al., 1998). In sheep, MUC-1 is also expressed on the apical surface of the LE and is downregulated during implantation to allow interactions of integrins and their ligands (Johnson et al., 2001a). Integrins comprise a family of intrinsic membrane proteins of noncovalently linked $\alpha$ and $\beta$ subunit heterodimers. Integrins serve as receptors and bind ECM and other ligands to aid in cellular adhesion, reorganization of cytoskeletal molecules or signal transduction (Miyamoto et al., 1995; Burghardt et al., 1997, in press). In sheep, integrin expression on the apical surface of the LE is constitutive (Johnson et al., 2001a). The ovine endometrial LE and trophectoderm express integrin subunits $\alpha_{v}, \alpha_{4}, \alpha_{5}, \beta_{1}, \beta_{3}$ and $\beta_{5}$ (Johnson et al., 2001a). The present study examined expression of the glycoprotein MUC- 1 and integrin subunits $\alpha_{v}, \alpha_{5}, \beta_{3}$ and $\beta_{5}$ by the endometrial epithelium of normal and UGKO ewes 14 days after mating. There were no differences between normal and UGKO ewes in the patterns of Muc-1 and integrin subunit expression on the endometrial LE. Previous 
studies have demonstrated similar results for temporal expression of steroid hormone receptors (Gray et al., 2000a) and LE-specific genes (Gray et al., 2001c) in the endometrium of UGKO compared with normal ewes. Taken together, the results of these studies support the contention that the endometrial LE of UGKO ewes is not abnormal in phenotype and is not the underlying cause of conceptus growth retardation and mortality.

In several species, conceptus implantation involves molecules that are secreted by the endometrial glands during pregnancy. In rodents, the endometrial glands secrete leucocyte inhibitory factor and calcitonin, which act on the uterine LE or conceptus to promote conceptus development, establishment of uterine receptivity and implantation (Carson et al., 2000). Available evidence from the ovine UGKO model supports the contention that the endometrial glands also secrete molecules that support conceptus survival and development. The endometrial glands of the pregnant ovine uterus synthesize and secrete osteopontin, which is hypothesized to play a role in conceptus attachment, adhesion and elongation during peri-implantation (Johnson et al., 1999a,b, 2001a). Osteopontin is a $70 \mathrm{kDa}$ acidic glycoprotein component of the ECM (Butler et al., 1996) that gives rise to 25 and $45 \mathrm{kDa}$ fragments upon treatment with proteases and freezing or thawing (Weber and Cantor, 1996). Osteopontin binds to cell surface integrins present on both trophectoderm and LE, via its RGD sequence present on the 70 and $45 \mathrm{kDa}$ forms, to promote cell-cell attachment during the period of implantation (Johnson et al., 1999b). Osteopontin engages a number of receptors, including the integrins $\alpha_{v}\left(\beta_{1}, \beta_{3}\right.$ or $\left.\beta_{5}\right)$ and $\left(\alpha_{4}, \alpha_{5}, \alpha_{8}\right.$ or $\left.\alpha_{9}\right) \beta_{1}$ (Denhardt et al., 2001). In the present study, osteopontin was found to be absent in uterine flushings from cyclic and UGKO ewes and present in all three forms in uterine flushings from pregnant ewes 14 days after mating. This pattern of osteopontin expression in normal ewes is similar to that reported by Johnson et al. (1999a). If osteopontin is essential for normal conceptus elongation and implantation in sheep, then its absence in the uterine milieu of UGKO ewes would be detrimental to conceptus survival and development, despite the presence of the integrin receptors for osteopontin on the endometrial LE. The process of conceptus elongation and implantation probably requires the interaction of ECM ligands and integrin receptors on the trophectoderm and endometrial LE (Johnson et al., 1999b, 2001a; Carson et al., 2000; Burghardt et al., in press). Results from the present study concur with this hypothesis and provide new insight into the physiology involved in ECM-mediated conceptus-uterine interactions involved in conceptus elongation and implantation in ruminants.

Another molecule that may be required for conceptus attachment during the peri-implantation period in the ovine uterus is GlyCAM-1 (Spencer et al., 1999b). GlyCAM-1 is a sulphated member of the mucin family of glycoproteins that is normally expressed by the endothelium of lymph nodes (Lasky et al., 1992). This glycoprotein serves as a ligand for
L-selectin which, in turn, activates integrins and promotes fibronectin adhesion to aid in extravasation of lymphocytes in lymph nodes (Rosen, 1993; Hwang et al., 1996; Giblin et al., 1997). In pregnant ewes, GlyCAM-1 in the LE and GE was low on days 11 and 13, increased on day 15, and was abundant on days 17 and 19 after mating (Spencer et al., 1999b). In pregnant ewes, the relative amount of immunoreactive GlyCAM-1 in uterine flushings was low on days 11 and 13, but high on days 15 and 17 after mating. Similar to findings for osteopontin, the abundance of GlyCAM-1 was low or undetectable in uterine flushings from cyclic and UGKO ewes, but was abundant in uterine flushings from pregnant ewes 14 days after mating. Thus, the absence of GlyCAM-1 in the uterine environment of UGKO ewes could also impede conceptus elongation and implantation. It is likely that several other molecules are also lacking in the UGKO uterus, resulting in conceptus mortality and growth retardation during the periimplantation period. The lack of a closed uterine lumen with discreet protruding caruncles may also contribute to defects in conceptus survival and elongation observed in UGKO ewes. However, available results support the hypothesis that defects in peri-implantation conceptus survival and growth in UGKO ewes are not the result of alterations in the endometrial expression of either antiadhesion molecules or integrin receptors, but are rather the result of an absence of endometrial glands and their secretions, including molecules involved in cell-cell adhesions such as osteopontin and GlyCAM-1. A functional genomics and proteomics approach will be necessary to determine which uterine factors are absent in UGKO ewes as compared with normal ewes during early pregnancy.

These studies were supported by Grants 1998-35203-6322 and 2001-35203-10700 from the NRI Competitive Grants Program/CSREES/USDA and, in part, by P30 ES09106. The authors appreciate the gift of reagents by $\mathrm{T}$. Hansen (University of Wyoming) and D. Carson (University of Delaware).

\section{References}

Ashworth CJ and Bazer FW (1989) Changes in ovine conceptus and endometrial function following asynchronous embryo transfer or administration of progesterone Biology of Reproduction 40 425-433

Bartol FF, Wiley AA, Coleman DA, Wolfe DF and Riddel MG (1988) Ovine uterine morphogenesis: effects of age and progestin administration and withdrawal on neonatal endometrial development and DNA synthesis Journal of Animal Science 66 3000-3009

Bartol FF, Wiley AA, Floyd JG, Ott TL, Bazer FW, Gray CA and Spencer TE (1999) Uterine differentiation as a foundation for subsequent fertility Journal of Reproduction and Fertility Supplement 54 285-300

Bazer FW (1975) Uterine protein secretions: relationship to development of the conceptus Journal of Animal Science 41 1376-1382

Bazer FW, Spencer TE and Ott TL (1997) Interferon tau: a novel pregnancy recognition signal American Journal of Reproductive Immunology 37 $412-420$

Bowen JA and Burghardt RC (2000) Cellular mechanisms of implantation in domestic farm animals Cell and Developmental Biology 11 93-104

Burghardt RC, Bowen JA, Newton GR and Bazer FW (1997) Extracellular matrix and the implantation cascade in pigs Journal of Reproductive Fertility Supplement 52 151-164 
Burghardt RC, Johnson GA, Jaeger LA, Ka H, Garlow JE, Spencer TE and Bazer FW Integrins and extracellular matrix proteins at the maternal-fetal interface in domestic animals Cells, Tissues and Organs (in press)

Butler WT, Ridall AL and McKee MD (1996) Osteopontin. In Principals of Bone Biology pp 167-181 Eds JP Bilezikian et al. Academic Press, New York

Carson DD, DeSouza MM, Kardon R, Zhou X, Lagow E and Julian J (1998) Mucin expression and function in the female reproductive tract Human Reproduction Update 4 459-464

Carson DD, Bagchi I, Dey SK, Enders AC, Fazleabas AT, Lessey BA and Yoshinaga K (2000) Embryo implantation Developmental Biology 223 $217-237$

Choi Y, Johnson GA, Burghardt RC, Berghman LR, Joyce MM, Taylor KM, Stewart MD, Bazer FW and Spencer TE (2001) Interferon regulatory factor two restricts expression of interferon- stimulated genes to the endometrial stroma and glandular epithelium of the ovine uterus Biology of Reproduction 65 1038-1049

Denhardt DT, Giachelli CM and Rittling SR (2001) Role of osteopontin in cellular signaling and toxicant injury Annual Review of Pharmacological Toxicology 41 723-749

Farin CE, Imakawa K and Roberts RM (1989) In situ localization of mRNA for the interferon, ovine trophoblast protein 1 , during early embryonic development of the sheep Molecular Endocrinology 3 1099-1107

Fazleabas AT, Hild-Petito S and Varhaage HG (1994) Secretory proteins and growth factors of the baboon (Papio anubis) uterus: potential roles in pregnancy Cell Biology International 18 1145-1153

Giblin PA, Hwang ST, Katsumo TR and Rosen SD (1997) Ligation of Lselectin on T lymphocytes activates $\beta 1$ integrins and promotes adhesion to fibronectin Journal of Immunology 159 3498-3507

Gray CA, Bartol FF, Taylor KM, Wiley AA, Ramsey WS, Ott TL, Bazer FW and Spencer TE (2000a) The ovine uterine gland knockout model: effects of gland ablation on the estrous cycle Biology of Reproduction 62 $448-456$

Gray CA, Taylor KM, Bazer FW and Spencer TE (2000b) Mechanisms regulating norgestomet inhibition of endometrial gland morphogenesis in the neonatal ovine uterus Molecular Reproductive Development $\mathbf{5 7}$ $67-78$

Gray CA, Bartol FF, Tarleton BJ, Wiley AA, Johnson GA, Bazer FW and Spencer TE (2001a) Developmental biology of uterine glands Biology of Reproduction 65 1311-1323

Gray CA, Bazer FW and Spencer TE (2001b) Effects of neonatal progestin exposure on female reproductive tract structure and function in the adult ewe Biology of Reproduction 64 797-804

Gray CA, Taylor KM, Ramsey WS, Hill JR, Bazer FW, Bartol FF and Spencer TE (2001c) Endometrial glands are required for pre-implantation conceptus elongation and survival Biology of Reproduction 64 1608-1613

Guillomot M (1995) Cellular interactions during implantation in domestic ruminants Journal of Reproduction and Fertility Supplement 49 39-51

Guillomot M, Fléchon J-E and Wintenberger-Torres S (1981) Conceptus attachment in the ewe: an ultrastructural study Placenta 2 169-182

Heyman Y, Camous S, Fevre J, Meziou W and Martal J (1984) Maintenance of the corpus luteum after uterine transfer of trophoblastic vesicles to cyclic cows and ewes Journal of Reproduction and Fertility 70 533-550

Hwang ST, Singer MS, Giblin PA, Yednock TA, Bacon KB, Simon SI and Rosen SD (1996) GlyCAM-1, a physiologic ligand for L-selectin, activates $\beta 2$ integrins on naive peripheral lymphocytes Experimental Medicine 184 1343-1348

Johnson GA, Burghardt RC, Spencer TE, Newton GR, Ott TL and Bazer FW (1999a) Ovine osteopontin II: osteopontin and $\alpha v \beta 3$ integrin expression in the uterus and conceptus during the periimplantation period Biology of Reproduction 61 892-899

Johnson GA, Spencer TE, Hansen TR, Austin KJ, Burghardt RC and Bazer FW (1999b) Expression of the interferon tau inducible ubiquitin crossreactive protein in the ovine uterus Biology of Reproduction 61 312-318

Johnson GA, Spencer TE, Burghardt RC, Joyce MM and Bazer FW (2000) Interferon-tau and progesterone regulate ubiquitin cross-reactive protein expression in the ovine uterus Biology of Reproduction 62 622-627
Johnson GA, Bazer FW, Jaeger LA, Ka H, Garlow JE, Pfarrer C, Spencer TE and Burghardt RC (2001a) Muc-1, integrin and osteopontin expression during the implantation cascade in sheep Biology of Reproduction $\mathbf{6 5}$ $820-828$

Johnson GA, Stewart MD, Gray CA, Choi Y, Burghardt RC, Yu-Lee LY, Bazer FW and Spencer TE (2001b) Effects of the estrous cycle, pregnancy, and interferon tau on 2',5'-oligoadenylate synthetase expression in the ovine uterus Biology of Reproduction 64 1392-1399

Kane MT, Morgan PM and Coonan C (1997) Peptide growth factors and preimplantation development Human Reproduction Update 3 137-157

Lasky LA, Singer M, Dowbenko D, Imai Y, Henzel W, Grimley C, Finnie C, Gillett N, Watson S and Rosen S (1992) An endothelial ligand for L-selectin is a novel mucin-like molecule Cell 69 927-938

Mirando MA, Short EC, Jr, Geisert RD, Vallet JL and Bazer FW (1991) Stimulation of $2^{\prime}, 5^{\prime}$-oligoadenylate synthetase activity in sheep endometrium during pregnancy, by intrauterine infusion of ovine trophoblast protein-1, and by intramuscular administration of recombinant bovine interferon- alpha 11 Journal of Reproduction and Fertility 93 599-607

Miyamoto S, Teramoto H, Coso OA, Gutkind JS, Burbelo PD, Akiyama SK and Yamada KM (1995) Integrin function: molecular hierarchies of cytoskeletal and signaling molecules Journal of Cell Biology 131 791-805

Roberts RM and Bazer FW (1988) The function of uterine secretions Journal of Reproduction and Fertility 82 875-892

Rosen SD (1993) L-Selectin and its biological ligands Histochemistry 100 185-191

SAS (1990) SAS User's Guide: Statistics Version 6. Statistical Analysis System Institute, Cary, NC

Simmen RCM and Simmen FA (1990) Regulation of uterine and conceptus secretory activity in the pig Journal of Reproduction and Fertility Supplement 40 279-292

Singer MS and Rosen SD (1996) Purification and quantification of Lselectin-reactive GlyCAM-1 from mouse serum Journal of Immunoligical Methods 196 153-161

Spencer TE, Becker WC, George P, Mirando MA, Ogle TF and Bazer FW (1995) Ovine interferon-tau inhibits estrogen receptor up-regulation and estrogen-induced luteolysis in cyclic ewes Endocrinology 136 4932-4944

Spencer TE, Stagg AG, Joyce MM, Jenster G, Wood CG, Bazer FW, Wiley AA and Bartol FF (1999a) Discovery and characterization of endometrial epithelial messenger ribonucleic acids using the ovine uterine gland knockout model Endocrinology 140 4070-4080

Spencer TE, Bartol FF, Bazer FW, Johnson GA and Joyce MM (1999b) Identification and characterization of glycosylation-dependent cell adhesion molecule 1-like protein expression in the ovine uterus Biology of Reproduction 60 241-250

Spencer TE, Gray CA, Ott TL, Johnson GA, Ramsey WS and Bazer FW (1999c) Differential effects of intrauterine and subcutaneous administration of recombinant ovine interferon tau on endometrial gene expression of cyclic ewes Biology of Reproduction 61 464-470

Steele RGD and Torrie JH (1980) Principles and Procedures of Statistics McGraw-Hill, New York

Stewart CL, Kaspar P, Brunet LJ, Bhatt H, Gadi I, Köntgen F and Abbondanzo SJ (1992) Blastocyst implantation depends on maternal expression of leukaemia inhibitory factor Nature 359 76-79

Stewart DM, Johnson GA, Vyhlidal CA, Burghardt RC, Safe SH, Yu-Lee LY, Bazer FW and Spencer TE (2001a) Interferon-tau activates multiple signal transducer and activator of transcription proteins and has complex effects on interferon-responsive gene transcription in ovine endometrial epithelial cells Endocrinology 142 98-107

Stewart DM, Johnson GA, Bazer FW and Spencer TE (2001b) Interferon-tau (IFNt) regulation of IFN-stimulated gene expression in cell lines lacking specific IFN-signaling components Endocrinology 142 1786-1794

Stewart MD, Choi Y, Johnson GA, Yu-Lee Ly LY, Bazer FW and Spencer TE (2002) Roles of Stat1, Stat2, and interferon regulatory factor-9 (IRF-9) in interferon tau regulation of IRF-1 Biology of Reproduction 66 393-400 
Swann SL, Bazer FW, Villarete LH, Chung A and Pontzer CH (1999) Functional characterization of monoclonal antibodies to interferon-tau Hybridoma 18 399-405

Van Heeke G, Ott TL, Strauss A, Ammaturo D and Bazer FW (1996) High yield expression and secretion of the ovine pregnancy recognition hormone interferon-tau by Pichia pastoris. Journal of Interferon and Cytokine Research 16 119-126

Weber GF and Cantor H (1996) The immunology of Eta-1/osteopontin Cytokines and Growth Factor Review 7 241-248

Wesseling J, Van der Valk SW, Vos HL, Sonnenberg A and Hilkens J (1995) Episialin (MUC-1) overexpression inhibits integrin mediated cell adhesion to extracellular matrix components Journal of Cell Biology 129 255-265

Zhu LJ, Bagchi MK and Bagchi IC (1998) Attenuation of calcitonin gene expression in pregnant rat uterus leads to a block in embryonic implantation Endocrinology 139 330-339

Received 11 February 2002.

First decision 27 March 2002.

Accepted 11 April 2002. 